\title{
Perancangan Sistem Smart Resto Mobile Reservation Client Server Multiplatform
}

\author{
Satria $^{1}$; Alfian Rosa Fitra ${ }^{2}$ \\ ${ }^{1,2}$ Program Studi Sistem Informasi, STMIK Bani Saleh \\ ${ }^{1}$ satria1905@gmail.com \\ 2fianfitra07@gmail.com
}

\begin{abstract}
ABSTRACK
Waroeng Steak And Shake is one of the favorite restaurants of Bekasi residents which in serving and payment ordering services is still using the manual method by taking notes on paper. This method is very ineffective because it still uses a lot of paper to record orders and cause long customer queues just to order food or pay for orders. Customers cannot provide special notes directly to the chef so orders are made according to standards. To overcome the problem of the length of the queue and the use of a lot of paper and customers can provide notes directly to the chef, the authors propose to design a smart resto mobile multiplatform server client server system with the waterfall method. The author hopes that this method can be implemented well in the system of ordering service records directly to the chef and of course reduce the queue at Waroeng Steak And Shake restaurant in Bekasi.
\end{abstract}

Keywords: Smart Resto, multiplatform, waterfall

\begin{abstract}
ABSTRAK
Waroeng Steak And Shake merupakan salah satu restoran favorit warga Bekasi yang dalam pelayanan pemesanan penyajian dan pembayaran masih menggunakan metode manual dengan mencatat dikertas. Metode ini sangat tidak efektif dikarenakan masih menggunakan kertas yang banyak untuk mencatat pesanan serta menimbulkan antrian pelanggan yang panjang hanya untuk memesan makanan maupun membayar pesanan. Pelanggan tidak dapat memberikan catatan khusus secara langsung ke koki sehingga pesanan dibuatkan sesuai standart. Untuk mengatasi permasalahan panjangnya antrian serta penggunaan kertas yang banyak dan pelanggan dapat memberikan catatan langsung ke koki maka penulis mengusulkan merancang sistem smart resto mobile reservation client server multiplatform dengan metode waterfall. Penulis berharap dengan metode ini dapat di implementasikan dengan baik dalam sistem pemesanan pelayanan catatan langsung ke koki dan tentunya mengurangi antrian di resto Waroeng Steak And Shake di Bekasi.
\end{abstract}

Kata Kunci : Smart Resto, multiplatform, waterfall 


\section{KILAT}

Vol. 9, No. 1, April 2020, P-ISSN 2089-1245, E-ISSN 2655-4925

DOI: https://doi.org/10.33322/kilat.v9i1.889

\section{PENDAHULUAN}

\subsection{Latar Belakang Masalah}

Era globalisasi informasi, dimana tekhnologi yang canggih melahirkan gaya hidup yang baru yaitu gaya hidup e-life atau electronik life dimana smartphone sebagai media alat elektronik yang berfungsi bukan hanya sekedar telekomunikasi seluler saja, melainkan dapat membantu memudahkan pekerjaan manusia. Dengan perkembang era telekomunikasi saat ini, smartphone dapat dijadikan suatu alat komunikasi yang dapat menunjang elektabilitas di restoran. Dimana smartphone dapat dijadikan media reservation dengan cara memanfaatkan fasilitas wifi. Dimana wifi bukan lagi hal yang mewah, dikarenakan restoran yang berkembang pasti memiliki fasilitas wifi gratis yang dapat dinikmati oleh pembeli. Permasalahan yang terdapat pada restoran waroeng steak and shake diantaranya, antrian pemesanan makanan yang terlalu lama. Padahal sifat manusia yang mudah bosan dan tidak sabar menjadi suatu alasan pelayanan harus cepat dan memuaskan. Jika menunggu terlalu lama hanya untuk memesan lambat laun pembeli akan bosan dan bisa mengakibatkan pelanggan berpindah restoran yang memiliki pelayanan yang memuaskan dalam hal pemesanan makanan. Hal ini merupakan ancaman bagi restoran karena dapat mengakibatkan berkurangnya pelanggan dan dapat menjadikan restoran bangkrut atau tidak laku. Selain itu juga faktor penggunaan bon kertas yang digunakan sebagai media pemesanan. Penggunaan kertas berlebih dapat berdampak terhadap lingkungan dan juga cost yang harus dikeluarkan untuk menyediakan kertas bon.

Maka dengan ini penulis membuat suatu sistem yang memudahkan transaksi pemesanan makanan di restoran waroeng steak and shake melalui media smartphone untuk client dan komputer maupun tablet untuk kasir atau pelayan dan juga bagian dapur. Dan ini merupkan suatu revolusi pada restoran, dengan memanfaatkan tekhnologi yang berkembang saat ini, dimana dulu pembeli harus mengantri hanya untuk sekedar memesan, saat ini pembeli dapat datang langsung kemudian memesan makanan sesuai keinginan mereka dan memberikan catatan pada pesanan tersebut melalui smartphone dengan menggunakan fasilitas wifi.

Client atau pembeli dapat menggunakan semua jenis smartphone sistem operasi baik itu andorid, ios, blackberry dan windows. Dikarenakan sistem ini akan berjalan pada multiplatform dan pemesanan melalui media wifi. Setelah masuk ke wifi pembeli harus memasukan passkey atau kode yang didapat dari receptionist.

\subsection{Tujuan Penelitian}

Tujuan dari pembuatan sistem smart resto mobile reservation client server multiplatform adalah:

a) Untuk mengatasi masalah pada restoran salah satunya pesanan yang lama dikarenakan banyaknya pengunjung yang lama untuk mengantri dalam memesan makanan

b) Untuk mengurangi dampak lingkungan dari efek penggunaan kertas di masa mendatang

c) Untuk memberikan kemudahan informasi antara pembeli dengan koki dalam memesan makanan sehingga koki tidak perlu lagi menunggu bon pesanan dari pelayan

d) Untuk membuat revolusi terbaru pada restoran dimana pembeli dapat memesan secara langsung dengan cara melalui fasilitas wifi di restoran, sehingga pelayanan menjadi efektif dan efisien. 


\section{METODE / RANCANGAN PENELITIAN}

\subsection{Metode Waterfall}

Menurut Rossa dan M. Shalahuddin (2014 : 28) menyimpulkan bahwa model SDLC air terjun (waterfall) sering juga disebut model sekuensial linier (sequential linear) atau alur hidup klasik (klasik lifecycle). Model air terjun menyediakan pendekatan alur hidup perangkat lunak secara sekuensial atau terurut dimulai dari analisis, desain, pengodean, dan pengujian. Berikut adalah gambar model air terjun:

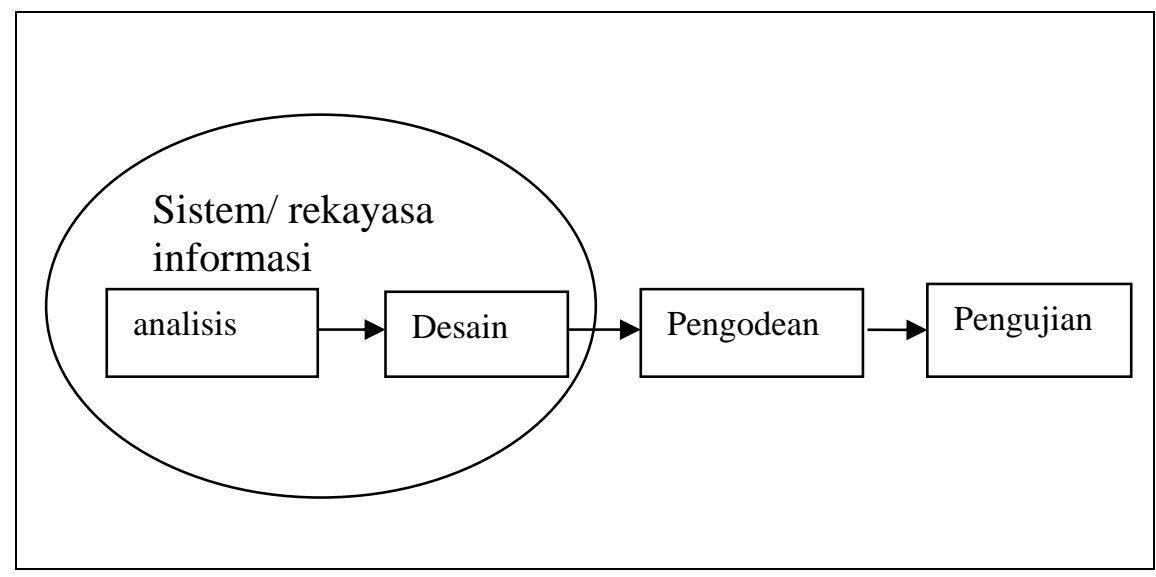

Sumber : Rosa A.S dan M.Shalahuddin

Gambar 1. Ilustrasi model waterfall

Berikut keterangan dari ilustrasi gambar model waterfall :

a. Analisis kebutuhan perangkat lunak

Proses pengumpulan kebutuhan dilakukan secara intensif untuk menspesifikasikan kebutuhan perangkat lunak agar untuk dapat dipahami perangkat lunak seperti apa yang dibutuhkan oleh user. Spesifikasi kebutuhan perangkat lunak pada tahap ini perlu untuk didokumentasikam.

b. Desain

Desain perangakat lunak adalah proses multi langkah yang fokus pada desain pembuatan program perangakat lunak termasuk struktur data, arsitektur perangkat lunak, representasi antar muka, dan prosedur pengodean. Tahap ini mentranlasi kebutuhan ke representasi desain agar dapat diimplementasikan menjadi program pada tahap selanjutnya. Desain perangkat lunak yang dihasilkan pada tahap ini juga perlu didokumentasikan.

c. Pembuatan kode program

Desain harus ditranslasikan ke dalam program perangkat lunak. Hasil dari tahap ini adalah program komputer sesuai dengan yang telah dibuat pada tahap desain.

d. Pengujian

Pengujian fokus pada perangkat lunak secara dari segi lojik dan fungsional dan memastikan bahwa semua bagian sudah diuji. Hal ini dilakukan untuk meminimalisir kesalahan (error) dan memastikan keluaran yang dihasilkan sesuai dengan yang diinginkan.

Dari kenyataan yang terjadi sangat jarang model air terjun dapat dilakukan sesuai alurnya karena sebab berikut:

a. Perubahan spesifikasi perangkat lunak yang terjadi ditengah alur pengembangan. 


\section{KILAT}

Vol. 9, No. 1, April 2020, P-ISSN 2089-1245, E-ISSN 2655-4925

DOI: https://doi.org/10.33322/kilat.v9i1.889

b. Sangat sulit bagi pelanggan untuk mendefinisikan semua spesifikasi di awal alur pengembangan. Pelanggan sering kali butuh contoh (prototype) untuk menjabarkan spesifikasi kebutuhan sistem lebih lanjut.

c. Pelanggan tidak mungkin bersabar mengakomodasikan perubahan yang diperlukan di akhir alur pengembangan.

Dengan berbagai kelemahan yang dimiliki model air terjun tapi model ini telah menjadi model dasar dari model-model lain dalam melakukan perbaikan model pengembangan perangkat lunak. Model air terjun ini sangat cocok digunakan kebutuhan pelanggan sudah dapat dipahami dan kemungkinan terjadinya perubahan kebutuhan selama pengembangan perangkat lunak kecil. Hal positif dari model air terjun adalah struktur tahap pengembangan sistem jelas, dokumentasi dihasilkan disetiap tahap sebelumnya selesai dijalankan (tidak ada tupang tindih pelaksanaan tahap).

\subsection{Sistem yang Berjalan}

Berdasarkan penelitian yang telah dilakukan oleh peneliti, maka dapat disimpulkan secara garis besar bahwa sistem yang sedang berjalan pada Resto Waroeng Steak And Shake dapat ditunjukan pada gambar activity diagram sebagai berikut:

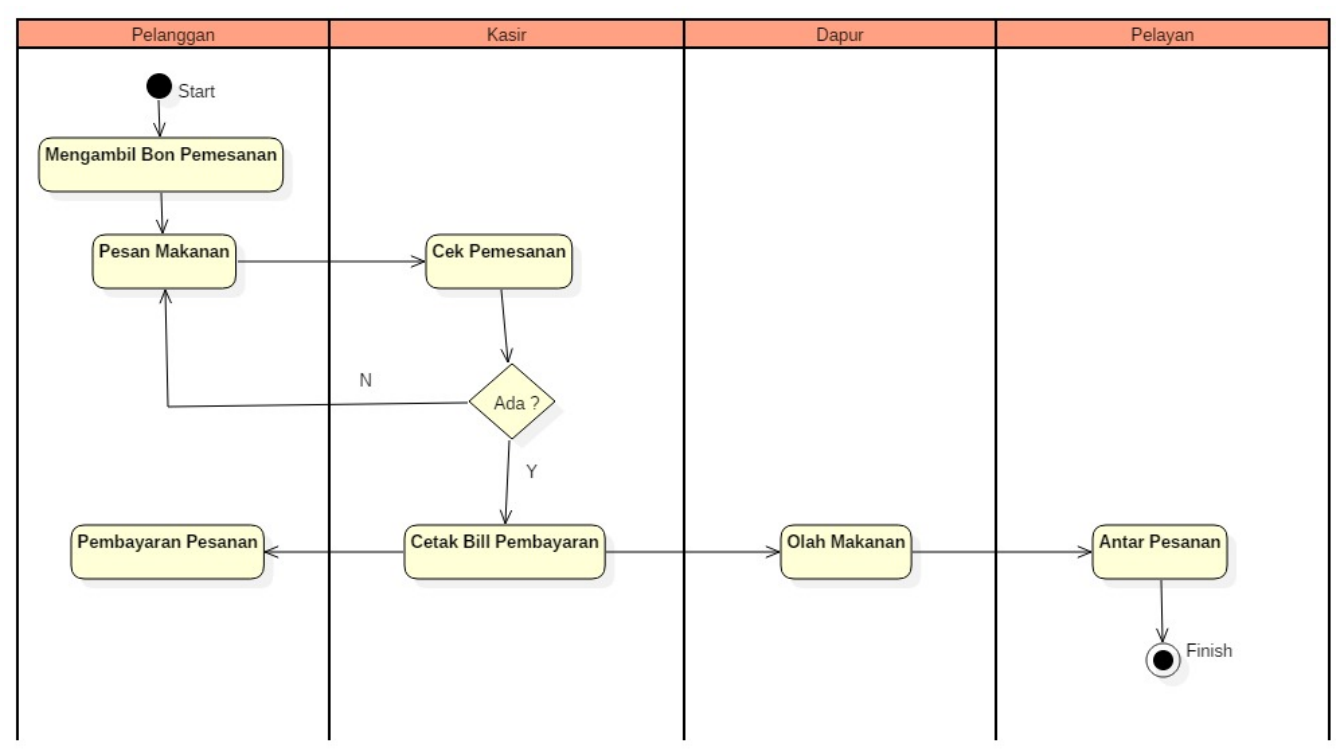

Gambar 2. Activity Diagram Yang Sedang Berjalan

Deskripsi Sistem Yang Berjalan :

a. Pelanggan

1) Pelanggan datang ke restoran kemudian mengambil daftar menu makanan di meja kasir setelah itu memesan makanan

2) Membayar sesuai sesuai tagihan dari kasir

b. Kasir

1) Mengecek pesanan pelanggan apakah masih tersedia atau sudah habis

2) Memberikan total biaya tagihan pesanan

3) Menerima total pembayaran dari pelanggan

c. Dapur

1) Mengolah makanan sesuai pesanan pelanggan yang didapatkan dari informasi kasir 


\section{d. Pelayan}

1) Mengantarkan pesanan ke meja pelanggan sesuai dengan pesanan

Berdasarkan sistem yang berjalan di Resto Waroeng Steak And Shake masih memiliki beberapa permasalahan, diantaranya, pemesanan makanan masih menggunakan metode manual dengan menulis di kertas pada daftar menu dan akan menimbulkan dampak yang tidak baik pada banyaknya penggunaan kertas di masa mendatang, kemudian pemesanan dan pembayaran dilakukan pada satu pelayan sehingga menyebabkan antrian panjang dan dapat menimbulkan dampak jangka panjang pelanggan akan pindah ke resto steak lainya dikarenakan malas untuk mengantri panjang. Selain itu dikarenakan antrian yang panjang dalam memesan makanan, terkadang menu yang sudah ditulis oleh pelanggan di daftar pesanan sudah habis, maka pelanggan harus memilih pesanan kembali dan kembali mengantri untuk memesan makanan. Kemudian kendala lainya yaitu pelanggan tidak dapat memberikan catatan khusus kepada koki sehingga pesanan dibuatkan secara standar masakan restoran.

\subsection{Sistem yang diusulkan}

Sistem smart resto ini menggunakan jaringan Wifi (Wireless Fidelity) sebagai media reservation, tidak menggunakan jaringan internet karena hanya dalam kawasan resto. Pelanggan harus terhubung dengan Wifi sehingga sistem dapat melakukan permintaan data menuju server, begitu sebaliknya server dapat merespon permintaan client.

Analisa awal sistem, pelanggan masuk ke restoran dan menerima Passkey dari recepsionist. Passkey digunakan hanya sekali pemesanan, itu dilakukan agar menghindari penipuan data dari pihak yang tidak bertanggung jawab. Passkey berbentuk kode unik yang dapat digunakan sebagai media cetak bill untuk pembayaran. Setelah pelanggan masuk dan menerima Passkey, pelanggan menghubungkan smartphone dengan jaringan wifi yang telah disediakan oleh resto, setelah terhubung maka secara otomatis akan masuk ke halaman menu login pemesanan, kemudian pelanggan dapat memasukan nama, nomor meja dan passkey yang di dapat dari receptionist, setelah itu pelanggan dapat masuk ke halaman pemesanan makanan, minuman maupun snack.

Pesanan dari pelanggan akan langsung masuk ke bagian dapur, dan bagian dapur akan memberi notifikasi pesanan apakah sudah di masak atau belum, jika belum di masak pesanan dapat di batalkan dan jika sudah di masak pesanan tidak dapat di batalkan. Pelanggan dapat menambah menu makanan sesuai keinginan dengan catatan pelanggan tidak keluar dari aplikasi tersebut karena fungsi dari passkey yang hanya dapat digunakan satu kali. Sembari menunggu pesanan pelanggan dapat memaksimalkan fasilitas wifi. Pesanan pelanggan dapat dilihat oleh receptionist kasir pada menu order list. Setelah selesai pelanggan dapat membayar sesuai tagihan yang tertera di menu bar total tagihan, pelanggan membayar di kasir dengan cara menunjukan passkey ataupun menyebutkan nomor meja sesuai pesanan. Setelah membayar kasir akan mencetak bill dan pelanggan dapat membayar sesuai tagihan. Kemudian pelanggan dapat memberikan rating dan komentar kepuasan pelanggan di resto tersebut. Passkey yang telah digunkan oleh pelanggan tersebut secara otomatis tidak dapat digunakan oleh pelanggan lain maupun pelanggan yang baru dating.

\subsection{Kelebihan Sistem Yang Diusulkan}

Berdasarkan sistem yang telah penulis usulkan maka penulis paparkan kelebihan-kelebihan dari sistem yang diusulkan tersebut, diantaranya :

a. Sistem ini akan memudahkan pelanggan dalam memesan makanan melalui smartphone dengan terhubung oleh akses wifi, sehingga pelanggan dapat memesan makanan tanpa 


\section{KILAT}

Vol. 9, No. 1, April 2020, P-ISSN 2089-1245, E-ISSN 2655-4925

DOI: https://doi.org/10.33322/kilat.v9i1.889

harus mengantri dan dapat memberikan catatan khusus kepada koki selera masakan yang diinginkan pelanggan.

b. Pada sistem ini dilengkapi dengan passkey yang berfungsi sebagai kode unik yang dapat digunakan untuk masuk ke menu pemesanan makanan oleh pelanggan serta pembayaran ke kasir, selain itu passkey hanya dapat digunakan satu kali sehingga tidak akan terjadi double pesanan ke satu pelanggan.

c. Sistem ini dapat diakses oleh pelanggan pada semua platform sistem operasi smartphone

\section{HASIL DAN PEMBAHASAN}

Use Case sistem smart resto mobile reservation dapat digambarkan sebagai berikut :

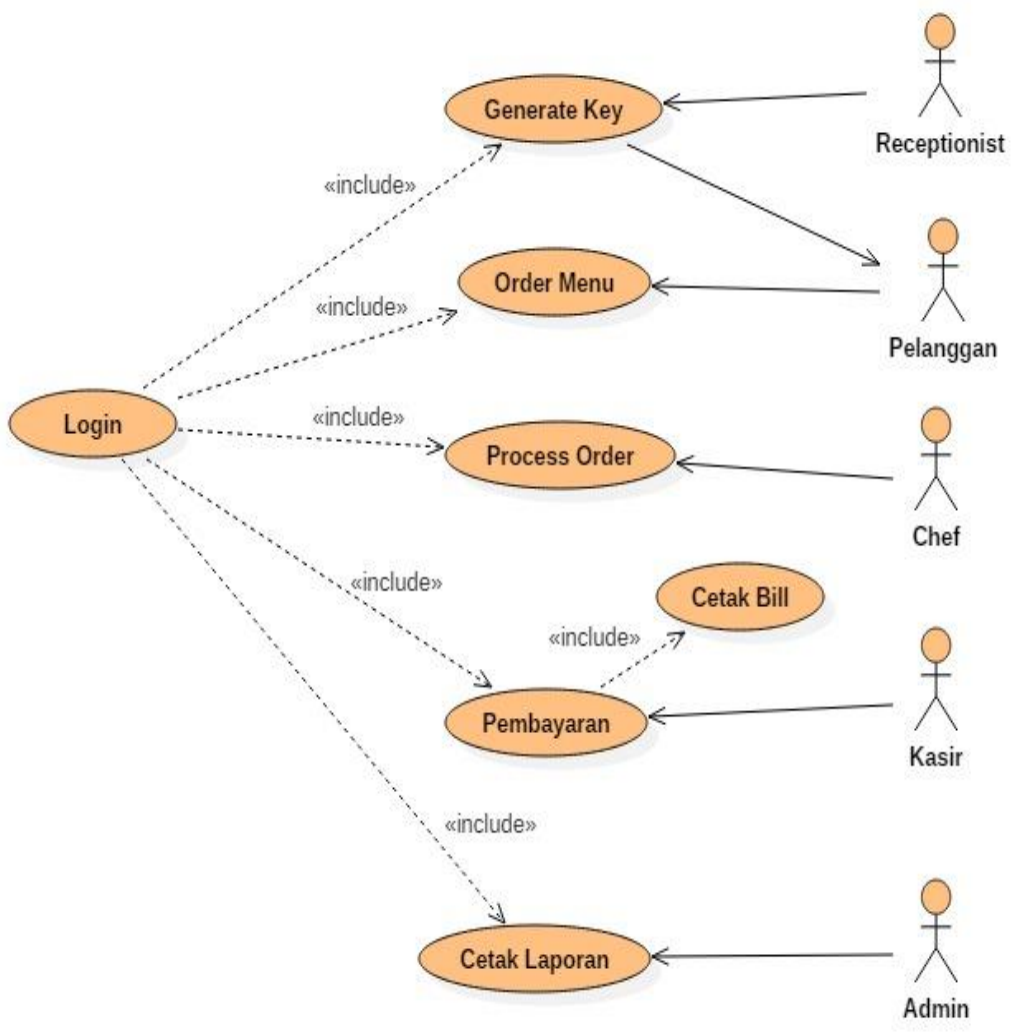

Gambar 3. Use Case Diagram

\subsection{Identifikasi Kebutuhan}

Dalam menjalankan sebuah sistem, terdapat aktor-aktor yang terlibat didalamnya. Baik itu berinteraksi dengan sistem, maupun proses-proses yang lainya. Pada sistem ini aktor-aktor yang terlibat pada sistem ini adalah :

a. Receptionist

Merupakan aktor yang berfungsi untuk melakukan generate key yang diberikan kepada pelanggan agar dapat melakukan proses pemesanan.

b. Pelanggan

Merupakan aktor yang melakukan pemesanan dengan memasukan passkey di form login yang telah diperoleh dari receptionist. 


\section{c. Chef}

Merupakan aktor yang berada di bagian dapur yang bertugas melakukan proses pemesanan sehingga notifiksi di pelanggan berubah menjadi sedang dimasak.

d. Kasir

Merupakan aktor yang berfungsi untuk menerima pembayaran pelanggan dengan menginputkan passkey yang telah diperoleh pelanggan dari receptionist.

e. Admin

Merupakan aktor yang berfungsi melakukan manajemen keseluruhan sistem, yang memiliki hak akses secara menyeluruh pada semua sistem sehingga dapat melakukan update delete maupun menambahkan sistem.

\subsection{Form Login Client Mobile}

Halaman login ini digunakan oleh client, dimana dapat diakses melalui mobile smartphone secara langsung dari client. Dengan syarat terhubung wifi waroeng steak and shake, dengan demikian client akan diarahkan ke menu login dan memasukan nama, nomor meja dan passkey yang didapatkan dari receptionist.

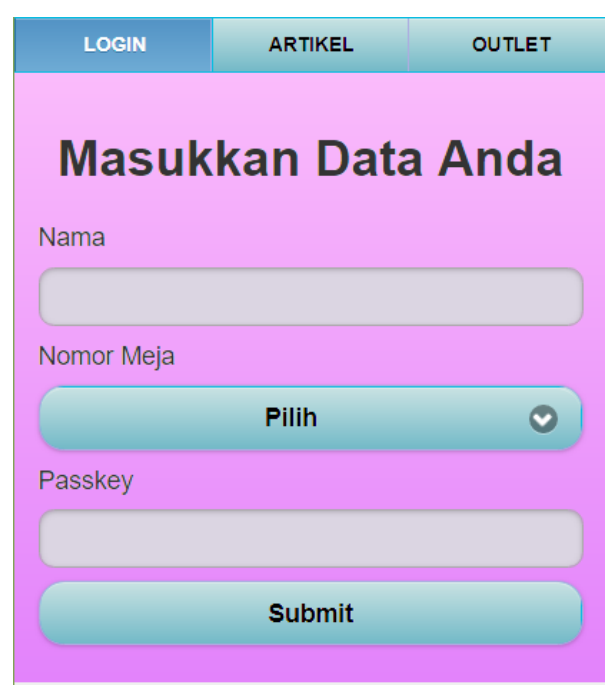

Gambar 4. Halaman Login Client

\subsection{Halaman Order Client}

Halaman ini ialah process order yang dilakukan oleh client secara langsung melalui mobile smartphone, dimana setiap client melakukan pemesanan maka akan secara langsung muncul total tagihan pembayaran, dan client dapat memberikan catatan masakan seperti pedas atau tidak. 


\section{KILAT}

Vol. 9, No. 1, April 2020, P-ISSN 2089-1245, E-ISSN 2655-4925

DOI: https://doi.org/10.33322/kilat.v9i1.889

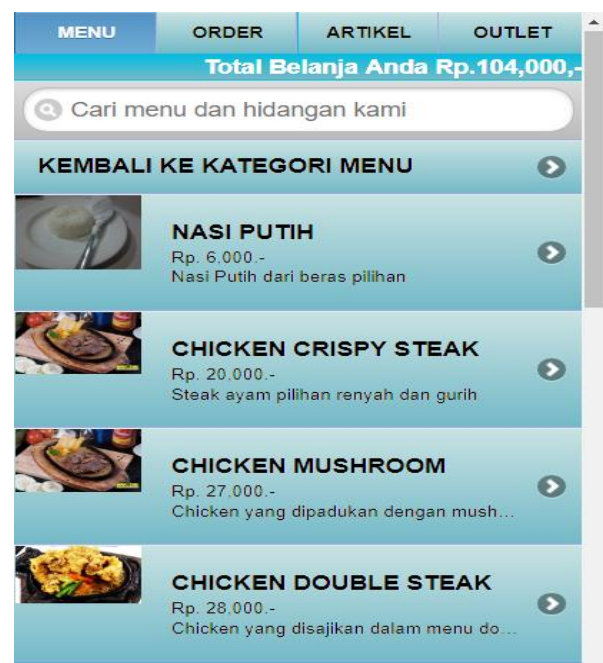

Gambar 5. Halaman Order Client

\subsection{Halaman History Order Client}

Halaman ini digunakan untuk melihat history pemesanan yang telah dilakukan oleh client lengkap dengan total tagihan, dan apabila pesanan belum diproses oleh dapur maka pesanan dapat dibatalkan dan apabila pesanan sudah di proses oleh dapur pesanan tidak dapat dibatalkan.

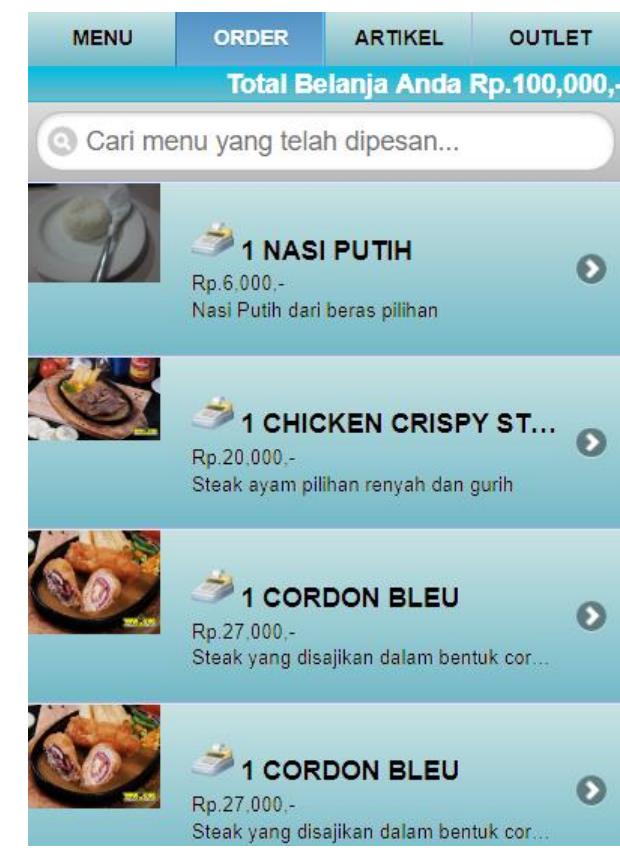

Gambar 6. Halaman Order Client

\subsection{Halaman Home Dapur}

Halaman ini hanya dapat diakses oleh dapur yang bertugas melakukan process masak 


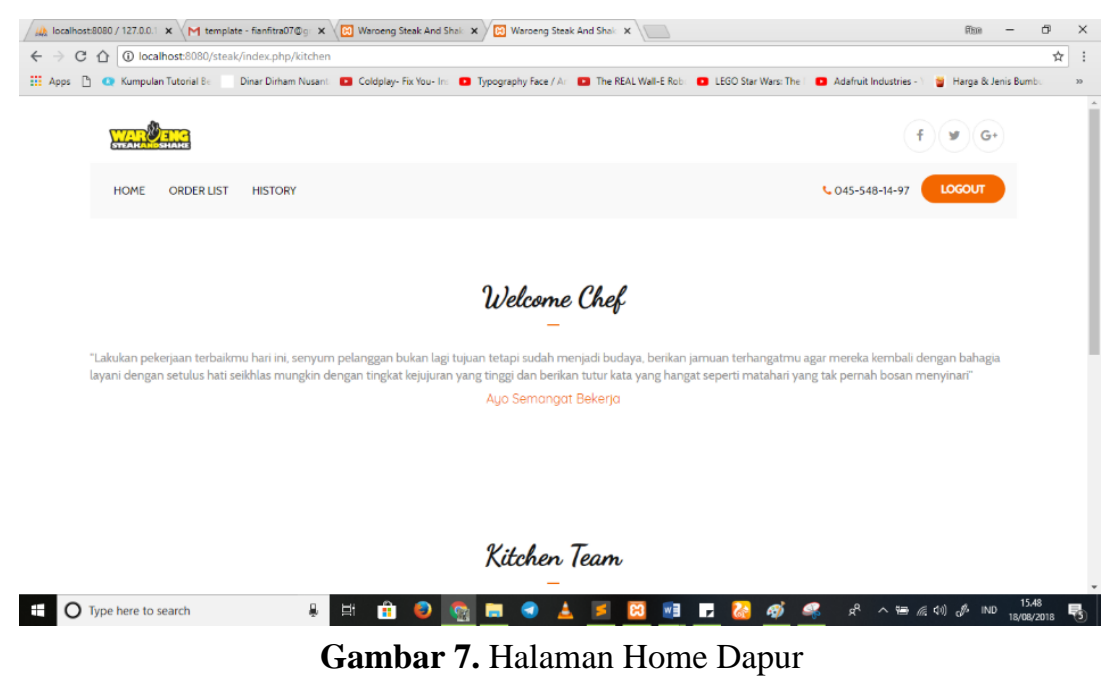

\subsection{Halaman Process Masak}

Halaman ini berfungsi untuk melakukan process masak yang dilakukan oleh dapur agar status pemesanan pada client menjadi OK dan pemesanan tidak dapat dibatalkan

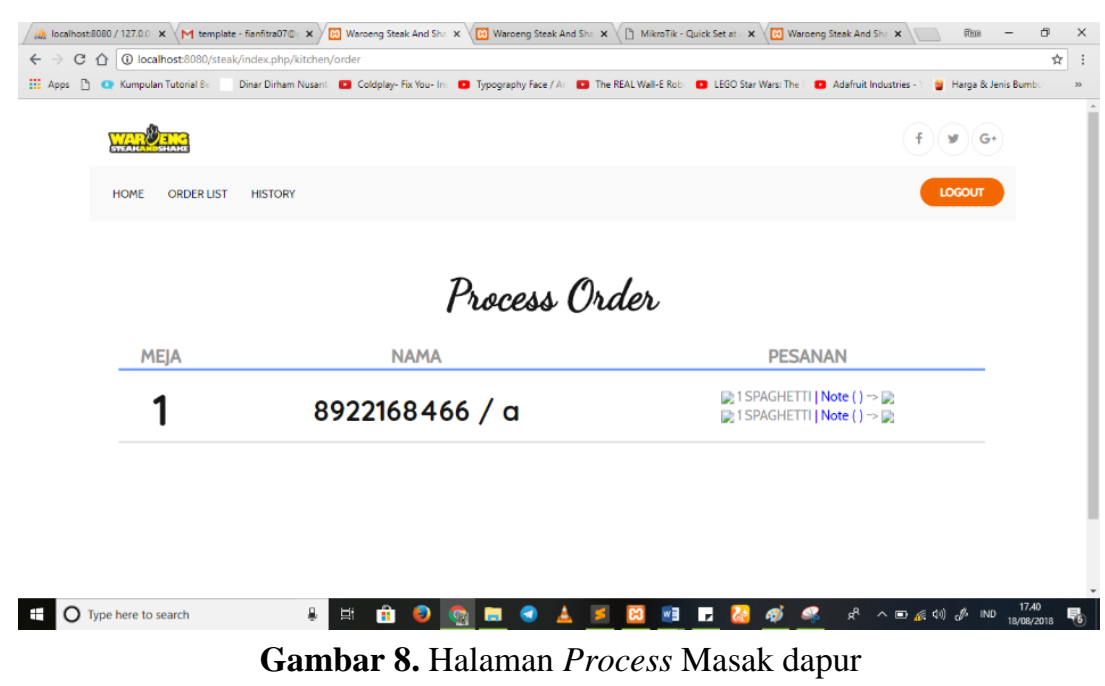

\subsection{Halaman Monitor Pesanan}

Halaman ini berfungsi untuk melihat pesanan yang telah masuk dan menandakan pesanan sudah diproses oleh dapur atau dibatalkan oleh client. 


\section{KILAT}

Vol. 9, No. 1, April 2020, P-ISSN 2089-1245, E-ISSN 2655-4925

DOI: https://doi.org/10.33322/kilat.v9i1.889

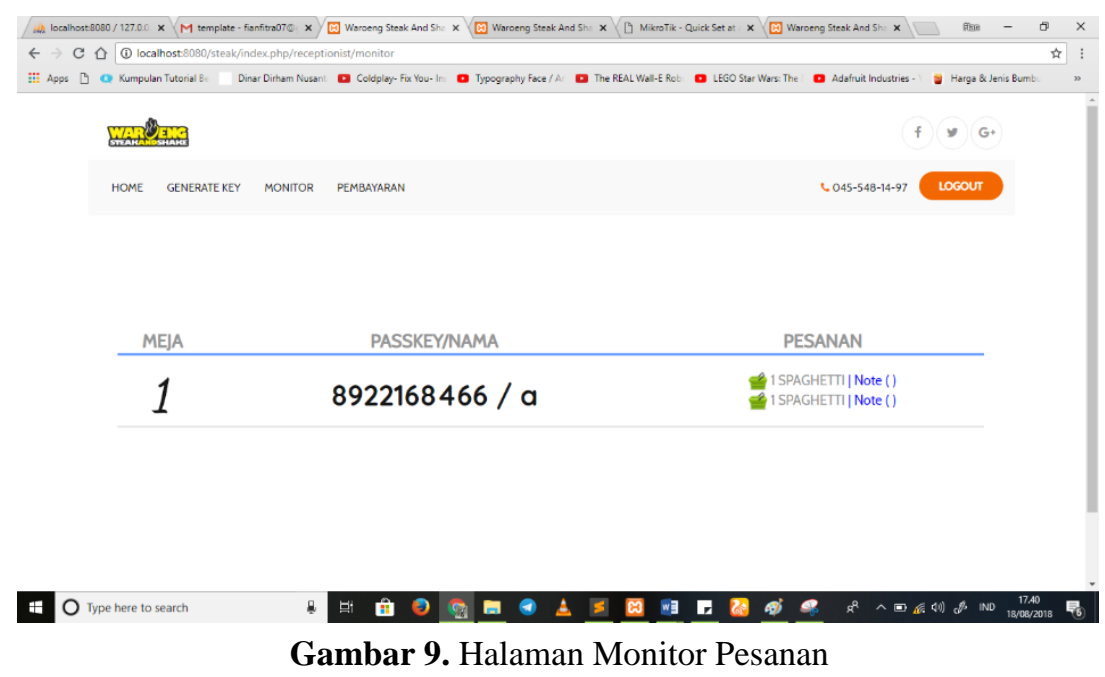

\subsection{Halaman Pembayaran}

Pembayaran dapat dilakukan dengan menginputkan passkey pelanggan

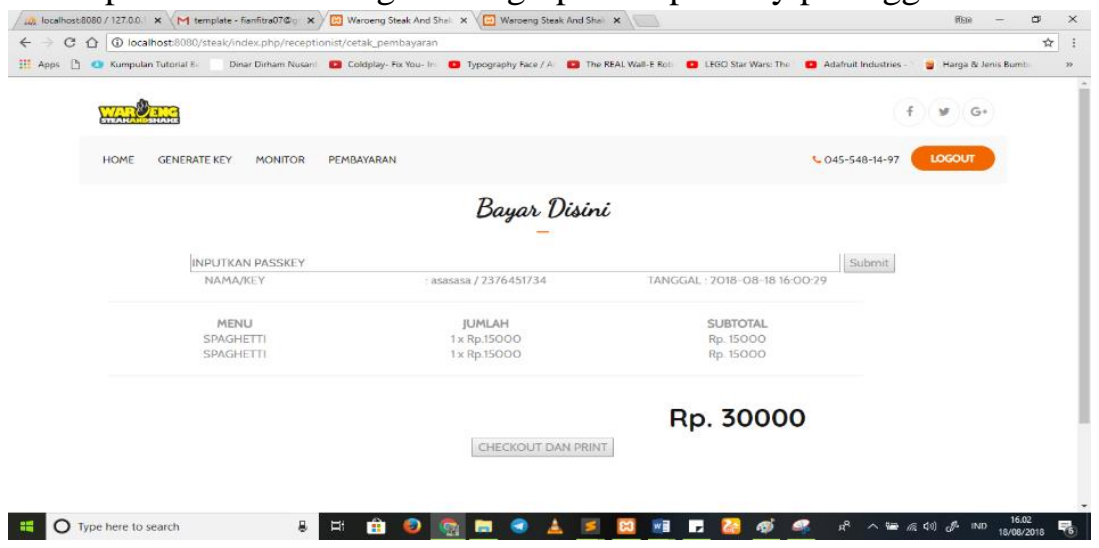

Gambar 10. Pembayaran

\subsection{Halaman Report}

Berikut ini report yang dapat diakses di menu admin yang berbentuk diagram batang dan tabel, untuk report tabel dapat di export ke file xls.

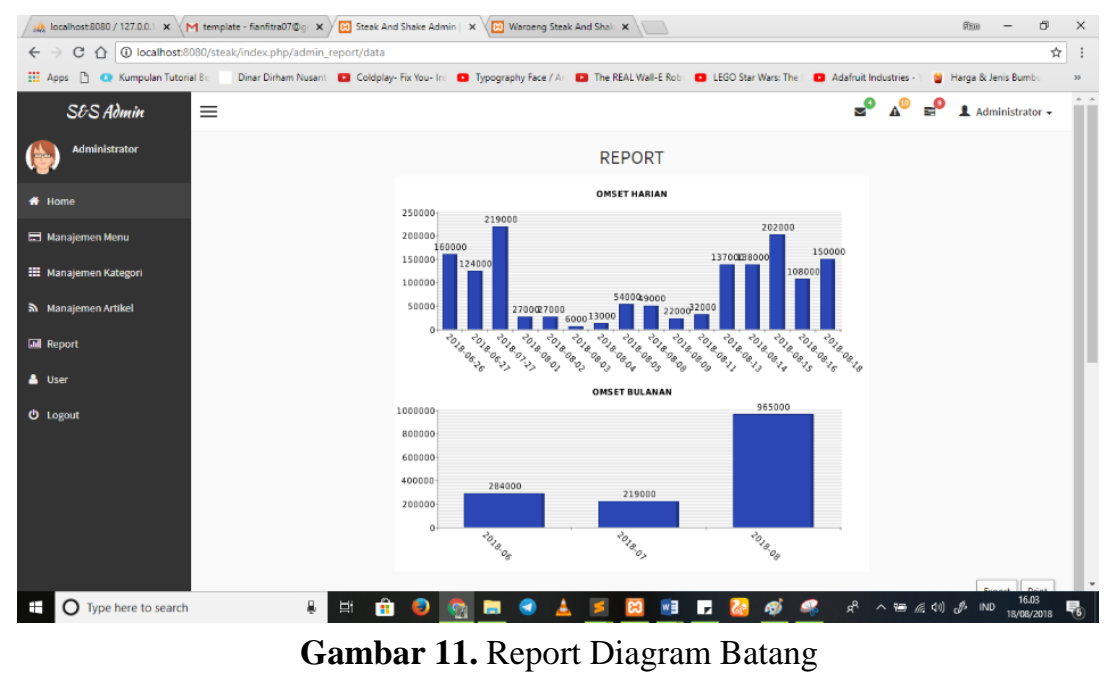




\section{KESIMPULAN DAN SARAN}

\subsection{Kesimpulan}

1. Sistem smart resto dapat dijadikan solusi untuk mengurangi antrian panjang untung memesan makanan.

2. Dengan adanya fitur passkey, dapat mengurangi penggunaan bon kertas yang berlebih.

3. Pada sistem ini client dapat memberikan catatan khusus kepeada chef mengenai masakan yang mereka inginkan

4. Tekhnologi ini dapat menjadi suatu solusi dalam pemesanan makanan pada restoran mengingat gaya hidup masyarakat yang sudah berubah menjadi $e$-life, dimana masyarakat yang sudah tidak bisa lepas dari smartphone.

\subsection{Saran}

1. Pada pengembangan sistem ini diharapkan dapat memesan makanan melalui sistem qrcode sehingga pelanggan tidak perlu mengetik, hanya tinggal meninggalkan scan melalui smartphone.

2. Pada menu client ditambahkan fitur yang lebih menarik, misal kumpulan video yang inspiratif, kemudian game dan juga fitur feedback jika ada kritik dan saran yang langsung masuk ke manager outlet

\section{UCAPAN TERIMAKASIH}

Penulis mengucapkan terima kasih kepada Instansi STT PLN yang telah memberi dukungan yang membantu pelaksanaan penelitian dan atau penulisan artikel

\section{DAFTAR PUSTAKA}

[1] AS, Rossa dan Shalahuddin, M. 2014. Rekayasa Perangkat Lunak Terstruktur dan Berorientasi Objek. Informatika. Bandung

[2] Bagyono dan Sambodo, Agus. 2010. Dasar-dasar Kantor Depan Hotel. CV.Andi Offset. Yogyakarta

[3] Busran, 2016. Perancangan Aplikasi Pemesanan Makanan Dan Minuman Berbasis Sistem Operasi Android. ISSN:2338-2724. Jurnal TEKNOIF. Vol. 4 No. 1 April 2016.

[4] Inayati, Immah. 2015. Aplikasi Pemesanan Makanan berbasis Web. ISSN : 2407-7712. ejurnal NARODROID. Vol. 1 No.2 Juli 2015.

[5] Muharto, Ambarita Arisandy. Metode Penelitian Sistem Informasi. 2016. Deepublish. Yogyakarta

[6] Mulhim Imam. 2013. Aplikasi Toko Bangunan Online dengan PHP dengan MYSQL. Maxikom. Palembang

[7] Mulyanto, Agus. 2009. Sistem Informasi Konsep dan Aplikasi. Pustaka Pelajar. Yogyakarta

[8] Ninemeier \& Hays. 2011. Restaurant Operations Management. New Jersey: Personal Prentice Hall

[9] Nugroho, Adi. 2010. Rekayasa Perangkat Lunak Menggunakan UML dan Java. Andi Offset. Jakarta

[10] Williams and Sawyer. 2011. Using Information Technology: A Practical Introduction to Computers \& Communications. McGraw-Hill. New York 